\title{
EVALUASI PROSEDUR PEMUNGUTAN CUKAI MINUMAN BERALKOHOL BUATAN DALAM NEGERI PADA KANTOR PENGAWASAN DAN PELAYANAN BEA DAN CUKAI TIPE MADYA PABEAN C KENDARI
}

\author{
Jenni Febriyanti Kapantouw \\ Inggriani Elim \\ Lidia Mawikere \\ Fakultas Ekonomi dan Bisnis Jurusan Akuntansi
Universitas Sam Ratulangi
Email : Jennifebriyantikapantouw@yahoo.co.id
}

ABSTRACT

Excise levies is one component of state revenues that have specific characteristics and different from other tax levies, one type of goods subject to excise that need to be monitored and controlled production and circulation ie excise beverages containing ethyl alcohol, or also known as non-alcoholic beverages. The purpose of this study is to evaluate the tax collection procedure alcoholic beverages domestically. This type of research is qualitative descriptive study to give a clear picture of the issues examined. The results obtained that the procedures for collecting excise alcoholic beverages domestically in KPPBC TMP C Kendari indeed in accordance with Law No. 39 of 2007 concerning amendments to the Law No. 11 Year 1995 on Customs, but there are some provisions excise alcoholic beverages artificial in the country that need to be refined in the regulations by the Director General of Customs and Excise KPPBC TMP C Kendari. TMP C Kendari KPPBC should more thoroughly in the collection of the alcoholic beverage excise, so hope that KPPBC Kendari TMP C is more active in activities such as dissemination to entrepreneurs factory.

Keywords: Evaluation Procedures, Collection of Customs.

\section{PENDAHULUAN}

\section{Latar Belakang}

Perkembangan ilmu pengetahuan dan teknologi sekarang ini berkembang sangat pesat. Hal itu juga berpengaruh pada pertumbuhan ekonomi yang mengalami peningkatan. Salah satu negara yang mengalami peningkatan ekonomi yaitu Indonesia, yang sampai saat ini masih berstatus sebagai negara berkembang yang artinya masih sangat membutuhkan banyak dana untuk membiayai pembangunan dan kebutuhan lainnya. Salah satu usaha pemerintah Indonesia untuk membiayai pembangunan yaitu dengan cara meminjam dana dari luar negeri. Saat ini untuk mendapatkan pinjaman dari luar negeri tidak gampang dan kenyataannya walaupun dana pinjaman sudah ada, masih belum cukup untuk memenuhi pembiayaan pembangunan di Indonesia. Untuk itu, maka pemerintah Indonesia terus meningkatkan pendapatan negara melalui sektor pajak dan bea cukai. (Mahmud 2015).

Pungutan cukai merupakan salah satu komponen penerimaan negara yang memiliki ciri khusus dan berbeda dengan pungutan pajak lainnya. Ciri khusus yang dimaksud adalah adanya sifat dan karakteristik tertentu pada objek yang dikenakan cukai. Hal ini seperti yang tertuang pada Undang-undang Nomor 11 Tahun 1995 tentang Cukai disadari masih terdapat hal-hal yang belum tertampung untuk memberdayakan peranan cukai sebagai salah satu sumber penerimaan negara sehingga Undang-undang Nomor 11 Tahun 1995 perlu diubah sejalan dengan perkembangan sosial ekonomi dan kebijakan pemerintah, maka dari itu dibuatlah Undang-undang Nomor 39 Tahun 2007 tentang Cukai sebagai perubahan atas Undang-undang Nomor 11 Tahun 1995.

Barang kena cukai tersebut merupakan barang-barang dengan sifat dan karakteristik tertentu yang pemakaian dan peredarannya perlu diawasi dan dikendalikan. Perlu diawasi karena dapat menimbulkan efek negatif dalam jangka waktu yang panjang dan maksud dikendalikan yaitu agar 
supaya peredarannya tidak terjadi dengan bebas atau ada batasannya, maka dari itu dipungutlah yang namanya cukai.

Cukai juga memiliki kontribusi sangat besar terhadap peningkatan pendapatan negara, oleh karena itu pemerinah terus melakukan upaya pengawasan dan pemungutan agar terus memberikan kontribusi terhadap pendapatan negara, tetapi juga tidak menimbulkan efek negatif dalam jangka panjang atas konsumsi barang kena cukai tersebut. Salah satu instansi pemerintah yang bertugas dan bertanggungjawab untuk memungut bea dan cukai di wilayah Kendari adalah Kantor Pengawasan dan Pelayanan Bea dan Cukai. (Mahmud 2015)

Indonesia hanya menetapkan tiga komoditi yang dikenakan cukai seperti yang terdapat pada Undang-undang Nomor 39 Tahun 2007, penerimaan cukai diperoleh dari etil alkohol, Minuman Mengandung Etil Alkohol (MMEA) dan hasil tembakau. Salah satu jenis barang kena cukai yang perlu diawasi dan dikendalikan produksi dan peredarannya yaitu cukai minuman mengandung etil alkohol atau yang dikenal juga dengan minuman beralkohol. Minuman beralkohol yaitu salah satu jenis barang kena cukai yang telah banyak memberikan kontribusi terhadap pendapatan negara melalui pemungutan cukainya.(Ismitania 2012)

\title{
Tujuan Penelitian
}

Berdasarkan perumusan masalah diatas, maka tujuan dari penelitian ini adalah untuk mengevaluasi prosedur pemungutan cukai minuman beralkohol buatan dalam negeri berdasarkan Undang-undang No. 39 Tahun 2007 perubahan atas Undang-undang No. 11 Tahun 1995 Tentang Cukai.

\section{TINJAUAN PUSTAKA}

\begin{abstract}
Akuntansi
Akuntansi adalah suatu kegiatan jasa. Fungsinya adalah memberikan informasi kuantitatif, terutama yang bersifat keuangan, mengenai suatu entitas ekonomi yang dimaksudkan untuk digunakan dalam pengambilan keputusan ekonomi, sebagai dasar dalam memilih di antara beberapa alternatif (Lubis 2010:2). Menurut APB Statement No.4 yang dikutip Hery (2013:3) menyatakan Akuntansi adalah sebuah aktivitas jasa, dimana fungsinya adalah memberikan informasi kuantitatif, terutama informasi mengenai keuangan dan entitas ekonomi, yang dimaksudkan akan menjadi berguna dalam pengambilan keputusan ekonomi (dalam membuat pilihan diantara berbagai alternatif yang ada). Menurut American Institute of Certified Public Accountants (AICPA) yang dikutip Hery (2013:3) mengemukakan bahwa akuntansi adalah seni pencatatan, pengklasifikasian, dan pengikhtisaran transaksi dan peristiwa keuangan dengan cara tertentu dan dalam ukuran moneter, termasuk penafsiran atas hasil-hasilnya.
\end{abstract}

\section{Pajak}

Pajak adalah iuran rakyat kepada kas negara berdasarkan undang-undang sehingga dapat dipaksakan dengan tiada mendapat balas jasa secara langsung. Pajak dipungut penguasa berdasarkan norma-norma hukum untuk menutup biaya produksi barang-barang dan jasa kolektif untuk mencapai kesejahteraan umum (Widyaningsih 2011:2).

Pajak memiliki dua fungsi, yaitu:

1. Fungsi Penerimaan (Budgeter)

Pajak berfungsi sebagai sumber dana yang diperuntukkan bagi pembiayaan pengeluaranpengeluaran pemerintah. Contoh: dimasukkannya pajak dalam APBN sebagai penerimaan dalam negeri (Waluyo 2013:6).

2. Fungsi Mengatur (Reguler) 
Pajak berfungsi sebagai alat untuk mengatur atau melaksanakan kebijakan di bidang sosial dan ekonomi. Contoh: dikenakannya pajak yang lebih tinggi terhadap minuman keras, dapat ditekan. Demikian pula terhadap barang mewah (Waluyo 2013:6).

\section{Definisi Cukai}

Purwito (2010:408) menyatakan Cukai merupakan pungutan negara yang berbentuk pajak tidak langsung yang dibayarkan atas pembelian barang yang spesifik yang sering disebut dengan barang kena cukai.

\section{Karakteristik Cukai}

Di dalam Pasal 2 Undang-undang Nomor 39 Tahun 2007 tentang cukai, sifat dan krakteristik barang-barang tertentu adalah sebagai berikut:

1. Barang-barang tertentu yang mempunyai sifat atau karakteristik:

a. Konsumsinya perlu dikendalikan;

b. Peredarannya perlu diawasi;

c. Pemakaiannya dapat menimbulkan dampak negatif bagi masyarakat atau lingkungan hidup; atau

d. Pemakaiannya perlu pembebanan pungutan negara demi keadilan dan keseimbangan, dikenai cukai berdasarkan undang-undang.

2. Barang-barang sebagaimana dimaksud pada ayat (1) dinyatakan sebagai barang kena cukai.

\section{Tarif Cukai}

Tarif cukai diatur dalam Pasal 5 Undang-undang No. 37 Tahun 2007 tentang Cukai perubahan atas Undang-undang No. 11 Tahun 1995 tentang Cukai, yaitu:

1. Barang kena cukai berupa hasil tembakau dikenai cukai berdasarkan tarif paling tinggi:

A. Barang kena cukai berupa hasil tembakau dikenai cukai berdasarkan tarif paling tinggi:

a. $275 \%$ (dua ratus tujuh puluh lima persen) dari harga dasar apabila harga dasar yang digunakan adalah harga jual pabrik; atau

b. 57\% (lima puluh tujuh persen) dari harga dasar apabila harga dasar yang digunakan adalah harga jual eceran.

B. Untuk yang diimpor:

a. $275 \%$ (dua ratus tujuh puluh lima persen) dari harga dasar apabila harga dasar yang digunakan adalah nilai pabean ditambah bea masuk; atau

b. 57\% (lima puluh tujuh persen) dari harga dasar apabila harga dasar yang digunakan adalah harga jual eceran.

2. Barang kena cukai lainnya dikenai cukai berdasarkan tarif paling tinggi:

A. Untuk yang dibuat di Indonesia:

a. $1.150 \%$ (seribu seratus lima puluh persen) dari harga dasar apabila harga dasar yang digunakan adalah harga jual pabrik; atau

b. $80 \%$ (delapan puluh persen) dari harga dasar apabila harga dasar yang digunakan adalah harga jual eceran.

B. Untuk yang diimpor:

a. $1.150 \%$ (seribu seratus lima puluh persen) dari harga dasar apabila harga dasar yang digunakan adalah nilai pabean ditambah bea masuk; atau

b. $80 \%$ (delapan puluh persen) dari harga dasar apabila harga dasar yang digunakan adalah harga jual eceran.

3. Tarif cukai sebagaimana dimaksud pada ayat (1) dan ayat (2) dapat diubah dari persentase harga dasar menjadi jumlah dalam rupiah untuk setiap satuan barang kena cukai atau sebaliknya atau penggabungan dari keduanya. 
4. Penentuan besaran target penerimaan negara dari cukai pada Rancangan Anggaran Pendapatan dan Belanja Negara (RAPBN) dan alternatif kebijakan Menteri dalam mengoptimalkan upaya mencapai target penerimaan, dengan memperhatikan kondisi industri dan aspirasi pelaku usaha industri, disampaikan kepada Dewan Perwakilan Rakyat Republik Indonesia (DPR RI) untuk mendapat persetujuan.

5. Ketentuan lebih lanjut mengenai besaran tarif cukai sebagaimana dimaksud pada ayat (1) dan ayat (2), serta perubahan tarif sebagaimana dimaksud pada ayat (3) diatur dengan peraturan menteri.

\section{Cukai Minuman Beralkohol Buatan Dalam Negeri}

Dalam undang-undang cukai No. 39 Tahun 2007 minuman beralkohol disebut dengan minuman mengandung etil alkohol atau MMEA adalah semua benda cair yang lazim disebut minuman mengandung etil alkohol yang dihasilkan dengan cara peragian, atau dengan cara lainnya. Cukai atas minuman beralkohol terdiri atas minuman beralkohol buatan dalam negeri dan minuman beralkohol import.

\section{Penggolongan Cukai Minuman Beralkohol Buatan Dalam Negeri}

Cukai minuman beralkohol terdiri dari 3 golongan berdasarkan kadar alkohol yang terkandung, yaitu sebagai berikut:

1. Kadar $5 \%$ golongan $\mathrm{A}$

2. Kadar $5 \%$ sampai dengan $20 \%$ golongan $B$

3. Kadar diatas $20 \%$ golongan $\mathrm{C}$

Pungutan cukai terhadap minuman beralkohol terbagi atas pungutan cukai minuman beralkohol buatan dalam negeri dan pungutan cukai minuman beralkohol import.

\section{Penelitian Terdahulu}

Sinom Ariza (2006) meneliti tentang Evaluasi Prosedur Pemungutan Cukai Hasil Tembakau dan Perkembangan Penerimaannya Pada Kantor Pelayanan Bea dan Cukai Tipe A Surakarta. Tujuan dari penelitian ini untuk mengetahui prosedur pemungutan cukai hasil tembakau dan perkembangan penerimaannya pada kantor pelayanan bea dan cukai tipe A surakarta. Penelitian tersebut menggunakan metode Deskriptif, dan memperoleh hasil penelitian Prosedur pelunasan cukai tembakau dilakukan dengan pelekatan pita cukai. Perkembangan kontribusi penerimaan cukai dari tahun ke tahun meningkat. Persamaan dengan penelitian ini adalah peneliti sebelumnya meneliti topik yang sama yaitu mengevaluasi cukai dan melihat perkembangan penerimaannya di kantor pelayanan bea dan cukai. Perbedaannya adalah peneliti mengambil objek cukai minuman beralkohol sedangkan peneliti sebelumnya mengambil objek cukai hasil tembakau.

Dewi M Istamania (2012) meneliti tentang Analisis Kebijakan Pelekatan Pita Cukai Minuman Mengandung Etil Alkohol Buatan Dalam Negeri. Tujuan dari penelitian ini yaitu untuk mengetahui penerapan kebijakan pelekatan pita minuman mengandung etil alkohol buatan dalam negeri. Penelitian tersebut menggunakan metode Kualitatif, dan hasil penelitian menunjukkan bahwa pelaksanaan kebijakan pita cukai mempermudah Direktorat Jenderal Bea dan Cukai dalam mengawasi minuman beralkohol beredar di masyarakat namun tetap saja masih ada kendala waktu dalam melakukan pemesanan pita cukai. Persamaan Peneliti sebelumnya juga meneliti tentang cukai minuman alkohol buatan dalam negeri. Perbedaannya Peneliti sebelumnya lebih memfokuskan penelitian dengan cara pelunasan cukai melalui pelekatan pita cukai, sedangkan peneliti mencoba mengevaluasi pelunasan cukai minuman beralkohol dalam negeri dengan prosedur yang berlaku di kantor bea dan cukai wilayah Manado. 


\section{METODE PENELITIAN}

\section{Jenis Penelitian}

Sedarmayanti \& Syarifrudin (2011:25) menyatakan metode penelitian adalah pembahasan mengenai konsep teoritik berbagai metoda kelebihtan dan kelemahannya, yang dalam karya ilmiah dilanjutkan dengan pemilihan metoda yang digunakan. Dalam penelitian ini, penulis menggunakan penelitian deskriptif, jenis penelitian deskriptif merupakan suatu penelitian yang bersifat menggambarkan secara sistematis mengenai fakta, situasi dan aktivitas dari objek yang diteliti.

\section{Tempat dan Waktu Penelitian}

Penelitian ini dilaksanakan di Kantor Pengawasan dan Pelayanan Bea dan Cukai Tipe Madya Pabean C Kendari Jl. Konggoasa No. 3 Kendari Sulawesi Tenggara 93127. Penelitian ini dilakukan dalam kurun waktu 3 bulan dari bulan Maret sampai dengan bulan April tahun 2016.

\section{Sumber Data}

Dalam penelitian ini Penulis menggunakan data kualitatif yang berisi tentang prosedur pemungutan cukai minuman beralkohol buatan dalam negeri dengan tujuan ingin menggambarkan atau memaparkan mengenai kondisi pemungutan cukai minuman beralkohol buatan dalam negeri di KPPBC TMP C Kendari berdasarkan Undang-undang Nomor 39 Tahun 2007 perubahan atas Undangundang Nomor 11 Tahun 1995 Tentang Cukai.

\section{Teknik Pengumpulan Data}

Teknik pengumpulan data yang digunakan penulis adalah sebagai berikut ini:

1. Teknik Wawancara

Wawancara ialah proses komunikasi atau interaksi untuk mengumpulkan informasi dengan cara tanya jawab antara peneliti dengan informan atau subjek penelitian (Emzir, 2010:50). Teknik wawancara dilakukan dengan Tangya jawab dan diskusi langsung dengan pihak yang ditunjuk Kantor Pengawasan dan Pelayanan Bea dan Cukai Kendari untuk menjelaskan secara singkat mengenai pemungutan cukai minuman beralkohol buatan dalam negeri di KPPB TMP C Kendari.

2. Dokumentasi

Dengan mengumpulkan dokumen secara langsung di lapangan yaitu mengambil data berupa dokumen-dokumen yang berhubungan dengan penelitian secara langsung di ambil di Kantor Bea dan Cukai Kendari Dokumen yang diambil berupa dokumen pelengkap seperti slip pembayaran cukai dan beberapa peraturan tentang cukai minuman beralkohol.

3. Penelitian Kepustakaan

Penelitian kepustakaan yaitu pengumpulan data dengan cara membaca dan mempelajari sumber-sumber kepustakaan berupa buku-buku literature, peraturan perundang-undangan serta dokumen-dokumen yang berhubungan dengan penelitian yang dapat digunakan sebagai dasar teori yang melengkapi proses penyusunan skripsi ini.

\section{Metode Analisis Data}

Analisis data adalah proses penyederhanaan data ke dalam bentuk yang lebih mudah dibaca dan interpretasikan. Metode analisis yang digunakan dalam penelitian ini adalah metode deskriptif yang dimaksud untuk menggambarkan objek yang diteliti. Penelitian ini menganalisis tentang prosedur, bagaimana Kantor Pengawasan dan Pelayanan Bea dan Cukai Tipe Madya Pabean C Kendari melakukan cara pemungutan cukai minuman beralkohol buatan dalam negeri yang beredar di Kota Kendari berdasarkan Undang-undang Nomor 39 Tahun 2007 perubahan atas Undang-undang Nomor 11 Tahun 1995 Tentang Cukai. 


\section{PEMBAHASAN}

\section{Gambaran Umum Objek Penelitian}

Bea dan Cukai merupakan institusi global yang hampir semua Negara di dunia memilikinya. Bea Cukai merupakan perangkat Negara "konvensional" seperti halnya kepolisian, kejaksaan, pengadilan, ataupun angkatan bersenjata, yang eksistensinya telah ada sepanjang masa sejarah Negara itu sendiri. Fungsi Bea Cukai di Indonesia diyakini sudah ada sejak zaman kerajaan dahulu, namun belum ditemukan bukti-bukti tertulis yang kuat, kelembagaannya pada waktu itu masih bersifat lokal sesuai wilayah kerajaannya. Sejak VOC masuk, barulah Bea Cukai mulai terlembagakan secara nasional.

\section{Visi Kantor Pengawasan dan Pelayanan Bea dan Cukai TMP C Kendari}

Visi dari Kantor Pengawasan dan Pelayanan Bea dan Cukai Tipe Madya Pabean C Kendari yaitu menjadi kantor pengawasan dan pelayanan bea dan cukai yang membanggakan dalam kinerja dan citra.

\section{Misi Kantor Pengawasan dan Pelayanan Bea dan Cukai TMP C Kendari}

Misi yaitu memberikan pelayanan prima dan melaksanakan pengawasan yang efektif kepada industri perdagangan, pariwisata, dan masyarakat.

Tabel 4.1 Perbandingan prosedur sesuai Peraturan Direktur Bea dan Cukai dengan Prosedur yang terjadi di lapangan

No.

\section{Prosedur sesuai dengan}

Peraturan Direktur Jenderal Bea dan Cukai Nomor PER-

\section{1/BC/2014}

1 Pengenaan Pemungutan Cukai MMEA atau Minuman Beralkohol (termasuk minuman beralkohol buatan dalam negeri).

a. Cukai dipungut atas MMEA yang dikeluarkan dari pabrik. Dan minuman yang dikecualikan dari MMEA yaitu minuman yang mendapatkan fasilitas tidak dipungut cukai atau pembebasan cukai.

b. Cukai MMEA dihitung berdasarkan tarif cukai MMEA dan jumlah MMEA dalam liter.

\section{Prosedur yang terjadi di lapangan}

Pemungutan Cukai Minuman Beralkohol Buatan Dalam Negeri

a. Cukai dikenakan terhadap semua minuman beralkohol yang mengandung etil alkohol dengan kadar alkohol berapapun dan atas MMEA yang dikeluarkan dari pabrik. Kecuali minuman berakohol yang diproduksi secara tradisional.

b. Cara menghitung tarif cukai minuman beralkohol buatan dalam negeri yaitu digunakan tarif cukai MMEA spesifik dikalikan dengan berapa jumlah liter.
Ket.

Prosedur yang terjadi dilapangan telah sesuai dengan prosedur yang ada pada peraturan Dirjen Bea dan Cukai. 
2 Penetapan Tarif Cukai MMEA atau Minuman Beralkohol (termasuk minuman beralkohol buatan dalam negeri).

Tarif cukai MMEA ditetapkan oleh Kepala Kantor:

a. Untuk mendapatkan penetapan tarif cukai MMEA, Pengusaha pabrik mengajukan permohonan kepada kepala kantor sebelum memproduksi setiap merek, jenis, volume, kemasan, dan kadar etil alkohol MMEA.

b. Permohonan menggunakan formulir penetapan tarif cukai.

c. Permohonan wajib dilampiri dengan contoh label, dan hasil uji kadar etil alkohol yang telah dilakukan oleh instansi/lembaga yang terkait yang memiliki kewenangan untuk menguji kadar etil alkohol dan yang telah mendapatkan akreditas dari KAN untuk MMEA dalam negeri.

d. Kepala kantor akan menerbitkan keputusan penetapan tarif atau menolaknya dalam jangka waktu 5 hari kerja sejak permohonan diterima dengan lengkap.
Penetapan Tarif Cukai MMEA atau Minuman Beralkohol (termasuk minuman beralkohol buatan dalam negeri).

a. Pengusaha pabrik akan mendatangi Kantor Bea dan Cukai untuk mengajukan permohonan penetapan tarif cukai MMEA terhadap kepala kantor, sebelum pengusaha pabrik memproduksi minuman beralkohol tersebut.

b. Pengusaha pabrik harus mengisi formulir penetapan tarif cukai yang sudah tersedia di Kantor Bea dan Cukai.

c. Permohonan yang telah diisi oleh pengusaha pabrik wajib dilampirkan dengan contoh label, dan hasil uji kadar etil alkohol yang dilakukan oleh instansi yang telah mendapatkan akreditasi dari KAN.

d. Kepala Kantor akan menerbitkan surat keputusan penetapan tarif cukai dalam jangka waktu 5 (lima) hari kerja terhitung sejak tanggal penetapan.
Prosedur yang terjadi dilapangan telah sesuai dengan prosedur yang ada pada peraturan Dirjen Bea dan Cukai.

\section{Sumber: KPPBC TMP C Kendari}

Tabel 4.1 Perbandingan prosedur sesuai Peraturan Direktur Bea dan Cukai dengan Prosedur yang terjadi di lapangan

\section{Prosedur sesuai dengan \\ No. Peraturan Direktur Jenderal Bea dan Cukai Nomor PER- 01/BC/2014 \\ e. Apabila permohonan telah disetujui, maka kepala kantor akan menerbitkan Surat Keputusan Penetapan Tarif Cukai MMEA. Namun apabila permohonan ditolak, maka kepala kantor akan mengeluarkan surat penolakan dan alasan ditolaknya permohonan tersebut.}

f. Kepala kantor akan mengirimkan lembar salinan Keputusan Penetapan Tarif Cukai MMEA kepada Direktur

\section{Prosedur yang terjadi di lapangan}

Ket.

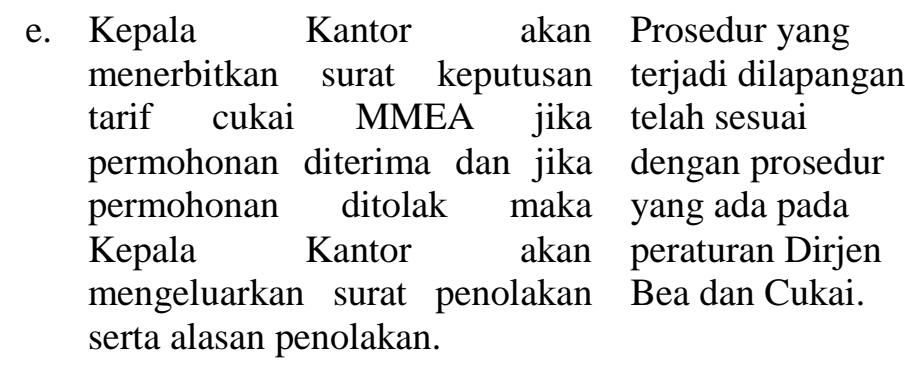

f. Dalam jangka waktu 5 (lima) hari kerja sejak tanggal penetapan kepala kantor harus mengirimkan lembar salinan keputusan penetapan tarif cukai MMEA beserta fotocopy berkas 
Cukai dan Kepala Kantor Wilayah dalam jangka waktu 5 hari kerja.

g. Apabila terdapat perubahan yang telah ditetapkan sebelumnya, maka Pengusaha Pabrik dan Importir wajib mengajukan kembali permohonan penetapan tarif cukai kepada Kepala Kantor.

h. Jika terjadi perubahan tarif cukai MMEA, maka Kepala Kantor akan menetapkan kembali tarif cukai MMEA tanpa didahului permohonan dari Pengusaha Pabrik.

i. Untuk penetapan kembali tarif cukai, harus menggunakan formulir penetapan kembali tarif cukai MMEA.

j. MMEA yang sudah mendapatkan penetapan tarif cukai, tidak boleh mengajukan penetapan tarif cukai kembali dengan kadar etil alkohol yang lebih rendah, yang dapat berakibat pada beban tarif cukai yang lebih rendah.

k. Keputusan Penetapan Tarif Cukai MMEA dapat dicabut jika Nomor Pokok Pengusaha Barang Kena Cukai dicabut. permohonan kepada Direktur Bea dan Cukai dan Kepala Kantor Wilayah.

g. Pengusaha pabrik atau importir akan mengajukan kembali permohonan kepada kepala kantor jika terdapat perubahan yang telah ditetapkan sebelum adanya perubahan tersebut.

h. Kepala kantor tidak boleh menetapkan kembali tarif cukai MMEA jika tidak didahului permohonan dari Pengusaha Pabrik atau Importir.

i. Formulir penetapan kembali tarif cukai MMEA harus digunakan jika pengusaha pabrik atau importir ingin menetapkan kembali tarif cukai tersebut.

j. Pengusaha pabrik atau Importir tidak boleh mengajukan penetapan kembali dengan kadar alkohol yang lebih rendah.

k. Jika nomor pokok pengusaaha barang kena cukai dicabut, maka keputusan penetapan tarif cukai MMEA tersebut ikut dicabut atau dapat dinyatakan batal.

\section{Sumber: KPPBC TMP C Kendari}

\section{Pembahasan}

Berdasarkan hasil perbandingan diatas, untuk tahap pemungutan cukai terhadap MMEA atau minuman beralkohol termasuk didalamnya minuman beralkohol buatan dalam negeri telah sesuai dengan prosedur yang terdapat dalam Peraturan Dirjen Bea dan Cukai dimana cukai dipungut atas MMEA yang dikeluarkan dari pabrik, hal ini telah sesuai dengan Undang-Undang Nomor 39 Tahun 2007 tentang Perubahan atas Undang-Undang Nomor 11 Tahun 1995 tentang Cukai yang menyatakan bahwa Cukai atas barang kena cukai yang dibuat di Indonesia dilunasi pada saat barang kena cukai tersebut dikeluarkan dari pabrik atau tempat penyimpanannya.

Prosedur penetapan tarif cukai MMEA untuk tahap pelunasan pada umumnya sudah berdasarkan dengan prosedur yang seharusnya. Namun dalam Peraturan Dirjen Bea dan Cukai, untuk pelaksanaan prosedur pelunasan cukai tidak dijelaskan tentang pemesanan pita cukai dengan menggunakan media elektronik. Pada Kantor Pengawasan dan Pelayanan Bea dan Cukai Tipe Madya Pabean C Kendari telah menggunakan Sistem Aplikasi Cukai Sentralisasi (SAC-S) yang terdapat pada media elektronik yang menggunakan jaringan internet, dengan cara langsung mengisi formulir CK-1A dan pada saat itu pula data yang diajukan oleh pengusaha pabrik sudah langsung terkirim sampai di Kantor Pusat Bea dan Cukai. Hal tersebut telah sesuai dengan Undang-Undang Nomor 39 Tahun 2007 pasal 3a ayat (1) tentang cukai yang menyatakan bahwa "Dokumen cukai dan/atau dokumen 
pelengkap cukai disampaikan dalam bentuk tulisan diatas formulir atau dalam bentuk data elektronik".

\section{PENUTUP}

\section{Kesimpulan}

Kesimpulan bahwa prosedur pemungutan cukai minuman beralkohol buatan dalam negeri sebenarnya telah sesuai dengan Undang-Undang Nomor 39 Tahun 2007 tentang Cukai. Namun, dalam Undang-Undang tersebut belum sepenuhnya mendukung untuk tata cara pemungutan cukai minuman beralkohol atau MMEA, karena dalam Undang-Undang Nomor 39 Tahun 2007 tersebut belum menjelaskan secara spesifik tentang ketentuan pemungutan cukai minuman beralkohol khususnya cukai tentang minuman beralkohol buatan dalam negeri yang sampai saat ini belum diatur lebih lanjut.

Saran

Saran bahwa Kantor Pengawasan dan Pelayanan Bea dan Cukai Tipe Madya Pabean C Kendari bisa terus meningkatkan kualitas dalam melaksanakan prosedur untuk pemungutan cukai minuman beralkohol buatan dalam negeri, karena telah melihat banyaknya jenis minuman beralkohol buatan dalam negeri yang telah banyak beredar di Kendari yang dapat berpotensi meningkatkan pendapatan negara. Oleh karena itu KPPBC TMP C Kendari lebih teliti lagi dalam pemungutan cukai minuman beralkohol tersebut, dan penulis berharap agar KPPBC TMP C Kendari ini lebih aktif lagi dalam kegiatan-kegiatan seperti sosialisasi kepada pengusaha-pengusaha pabrik tentang cukai khususnya cukai minuman beralkohol buatan dalam negeri dan tata cara pemungutannya, agar para pengusaha pabrik bisa mengerti dan memudahkan para pengusaha pabrik dalam hal ini pemungutan cukainya agar mencapai maksud dan tujuan dari Undang-Undang Nomor 39 Tahun 2007 tentang Perubahan atas Undang-Undang Nomor 11 Tahun 1995 tentang Cukai.

\section{DAFTAR PUSTAKA}

Ariza, Sinom, 2006. Evaluasi Prosedur Pemungutan Cukai Hasil Tembakau dan Proses Perkembangan Penerimaannya Di Kantor Pelayanan Bea dan Cukai Tipe A Surakarta. Tugas Akhir. Fakultas Ekonomi Universitas Sebelas Maret, Surakarta. http://eprints.uns.ac.id/2619. diakses 21 Februari 2016.

Ismitanisa, M, Dewi, 2012. Analisis Kebijakan Pelekatan Pita Cukai Minuman Mengandung Etil Alkohol Buatan Dalam Negeri. Skripsi. Fakultas Ilmu Sosial dan Ilmu Politik Universitas Indonesia. Depok.

http://www.google.com/url?sa=t\&rct=j\&q=\&esrc=s\&source=web\&cd=2\&cad=rja\&uact=8\&ve d=0CCUQFjAB\&url=http\%3A\%2F\%2Flib.ui.ac.id\%2Ffile\%3Dpdf\%2Fmetadata20320732.pdf\&ei=ELwFVa7GBIS7uAT5-

YGAAw\&usg=AFQjCNHbsZyawaheRUz0KSolywcSWIYnrA\&bvm=bv.88198703,d.c2E. Diakses 14 Maret 2016.

Lubis, Arfan Ikhsan, 2010. Akuntansi Keperilakuan. Penerbit Salemba Empat, Jakarta.

Mahmud, Lilyani,2015. Evaluasi Prosedur Pemungutan Cukai Minuman Beralkohol Buatan Dalam Negeri dan Perkembangan Penerimaannya Pada Kantor Pengawasan dan Pelayanan Bea dan Cukai Tipe Madya Pabean C Kendari. Skripsi. Fakultas Ekonomi dan Bisnis Universitasi Sam Ratulangi. Manado.

Pemerintah Republik Indonesia. 2007. Undang-Undang Nomor 39 Tahun 2007 atas Perubahan Undang-Undang Nomor 11 Tahun 1995 tentang Cukai, Jakarta.

Pemerintah Republik Indonesia. 2014. Peraturan Direktur Jenderal Bea dan Cukai Nomor PER01/BC.2014 tentang tata cara pemungutan cukai etil alkohol, minuman mengandung etil alkohol, dan konsentrat mengandung etil alkohol, Jakarta.

Purwito, Ali, 2010. Kepabeanan dan Cukai : (Pajak Lalu Lintas Barang) Konsep dan Aplikasi. Fakultas Hukum Universitas Indonesia, Jakarta.

Sedarmayanti, Syarifudin, 2011. Metodologi Penelitian. Mandar Maju, Bandung.

Waluyo. 2013. Perpajakan Indonesia. Salemba Empat, Jakarta Selatan.

Widyaningsih, Aristanti, 2011. Hukum Pajak dan Perpajakan. Penerbit Alfabeta, Bandung. 